\title{
Upaya Meningkatkan Kebiasaan Belajar Terhadap Prestasi Belajar Siswa Melalui Layanan Bimbingan Kelompok Dengan Teknik Self Management di MTs Muslimat NU Palangka Raya
}

\author{
M. Akbar Wibosono', Sunaryo A.12, Oktamia K. Sangalang 3 \\ Prodi BK FKIP Universitas Palangka Raya \\ E-mail: Akbar.greats@gmail.com
}

\begin{abstract}
ABSTRAK
Penelitian ini bertujuan untuk mengetahui adakah efektivitas bimbingan kelompok Teknik self-management dalam meningkatkan kebiasaan belajar terhadap prestasi belajar. Jenis penelitian ini adalah penelitian eksperimen. Teknik pengumpulan data menggunakan angket kebiasaan belajar dengan skala likert dan dokumen legger dari nilai hasil prestasi belajar yang dilakukan sebanyak 2 (Dua) kali pertemuan. Teknik analisis data menggunakan Uji-T berpasangan. Jumlah sampel penelitian 10 (Sepuluh) siswa. Teknik pengambilan sampel dalam penelitian ini dilakukan dengan sampling purposive. Dan perhitungan hasil yang menggunakan pre-test dan post-test one group design. Berdasarkan hasil penelitian yang telah dilakukan diperoleh hasil penggunaaan bimbingan kelompok melalui layanan bimbingan kelompok dengan teknik self-management sebelum diberi treatment hasil pretest skor rata-rata kebiasaan belajar 50 setelah diberi treatment berubah menjadi 68,5 dengan peningkatan 18,5. Sedangkan untuk nilai hasil prestasi belajar sebelum diberi treatment hasil nilai rata-rata legger pretest 70,1 setelah diberi treatment berubah menjadi 76,46 dengan peningkatan 6,36 . Hal ini membuktikan bahwa adanya peningkatan antara pretest dan posttest. Dari hasil penelitian yang telah dilakukan dan hasil uji hipotesis taraf kesalahan $5 \%$ jika $\mathrm{t}$ hitung $<\mathrm{t}$ tabel $\mathrm{db} \mathrm{n}-\mathrm{I}$ diketahui bahwa thitung kebiasaan belajar -9,62 I4 dan tabel2,262. Ini berarti thitung $>\mathrm{t}_{\text {tabel }}$ maka $\mathrm{H}_{\mathrm{o}}$ ditolak dan $\mathrm{H}_{\mathrm{a}}$ diterima sehingga disimpulkanbahwa bimbingan kelompok dengan menggunakan teknik self-management efektif meningkatkan kebiasaan belajar terhadap prestasi belajar siswa kelas IX-B MTs Muslimat NU Palangka Raya.
\end{abstract}

Kata Kunci: Bimbingan Kelompok; Teknik Self Management; Kebiasaan Belajar; Prestasi Belajar

\section{Efforts to Improve Study Habits on Student Achievement Through Group Guidance Services Using Self Management Techniques at MTs Muslimat NU Palangka Raya}

\begin{abstract}
This study aims to determine the effectiveness of group guidance self-management techniques in improving study habits on learning achievement. This type of research is experimental research. The data collection technique used a study habits questionnaire with a Likert scale and Legger documents from the value of learning achievement results carried out in 2 (two) meetings. The data analysis technique used paired T-test. The number of research samples is 10 (ten) students. The sampling technique in this study was done by purposive sampling. And the calculation of the results using the pre-test and post-test one group design. Based on the results of the research that has been carried out, the results obtained from the use of group guidance through group guidance services with selfmanagement techniques before being given treatment, the results of the pretest average score of 50 after being given treatment changed to 68.5 with an increase of 18.5. As for the value of learning achievement results before being given treatment, the average value of the legger pretest was 70.1 after being given treatment, it changed to 76.46 with an increase of 6.36. This proves that there is an increase between the pretest and posttest. From the results of the research that has been done and the results of hypothesis testing, the error rate is $5 \%$ if $t$ count $<t$ table $d b n-I$, it is known that tcount of study habits is $-9.62 / 4$ and ttable is 2.262 . This means that tcount $>$ ttable, $\mathrm{Ho}$ is rejected and $\mathrm{Ha}\urcorner$ is accepted, so it can be concluded that group guidance using self-management techniques is effective in improving study habits on student achievement in class IX-B MTs Muslimat NU Palangka Raya.
\end{abstract}

Keywords: Group Guidance; Self-management Technique; Learning Habit; Learning achievement 


\section{PENDAHULUAN}

Undang-Undang Dasar1945 Pasal 3I (I) dalam mengamanatkan bahwa setiap warga negara berhak mendapat pendidikan, hal ini berarti ada kewajiban dari Negara untuk melayani warganya untuk memperoleh pendidikan yang layak dalam rangka perbaikan kualitas hidup, mental dan spiritual (Yanti, 20I5). Selanjutnya menurut Undang-Undang Republik Indonesia Nomor 20 Tahun 2003 tentang Sistem Pendidikan Nasional. Pendidikan adalah usaha sadar dan terencana untuk mewujudkan suasana belajar dan proses pembelajaran agar peserta didik secara aktif mengembangkan potensi dirinya untuk memiliki kekuatan spritual keagamaan, pengendalian diri, kepribadian, kecerdasan, akhlak mulia, serta keterampilan yang diperlukan dirinya, masyarakat, bangsa dan negara (Fokusmedia, 20I5).

Adapun Kegiatan paling pokok dari seluruh proses pendidikan tersebut adalah belajar yang merupakan proses interaksi antara individu dengan sumber belajar yang menghasilkan suatu perubahan tingkah laku. Hal ini sejalan dengan pendapat Slameto (dalam Hanafy, 2014) bahwa belajar ialah suatu proses usaha yang dilakukan seseorang untuk memperoleh suatu perubahan tingkah laku yang baru secara keseluruhan, sebagai hasil pengalamannya sendiri dalam berinteraksi dengan lingkungannya. Perubahan yang dimaksud tidak hanya berkaitan dengan penambahan pengetahuan melainkan juga seperti yang diungkapkan Rosyid et al., (2019) berbentuk kecakapan, keterampilan, sikap dan perilaku, harga diri, minta watak dan penyesuian diri. Lebih lanjut dinyatakannya perubahan pada siswa yang menyangkut pengetahuan, tingkah laku akan menjadi tolak ukur keberhasilan siswa dalam belajar yaitu prestasi belajar, dimana hal tersebut menjadi titik akhir dalam menentukan keberhasilan siswa dengan kegiatan-kegiatan yang terencana dan terstandarisasi.
Oleh karena itu sekolah sebagai suatu lembaga pendidikan formal, secara sistematis merencanakan bermacam lingkungan, yaitu lingkungan pendidikan yang menyediakan bermacam kesempatan bagi siswa untuk melaksanakan berbagai kegiatan belajar, sehingga para siswa memperoleh pengalaman pendidikan.Selanjutnya istilah prestasi belajar (achievement) berbeda dengan hasil belajar (learning outcome).

Aripin (dalam Rosyid et al., (2019) mengungkapkan prestasi belajar berkenaan dengan aspek knowledge (pengetahuan) sedangkan hasil belajar berhubungan dengan pembentukan watak (behavior).Berkenaan dengan prestasi belajar Djamarah (dalam NK Pratiwi, 2017) menyatakan bahwa prestasi belajar adalah penilaian pendidikan tentang kemajuan siswa dalam segala hal yang dipelajari disekolah yang menyangkut pengetahuan dan keterampilan yang dinyatakan sesudah hasil evaluasi pendidikan yang diwujudkan bentuk angka, huruf atau simbol maupun kalimat yang menyatakan keberhasilan siswa dalam proses pendidikan yang disepakati oleh pihak penyelenggara pendidikan.Siswa yang beprestasi tentunya juga diharapkan akan mampu menyelesaikan studinya dengan tepat waktu. Untuk dapat meraih prestasi sangat dipengaruhi oleh banyak faktor yang mendukung, baik itu yang berasal dari dalam diri maupun dari luar diri.

Berkaitan dengan itu Hamalik (2020) mengemukakan bahwa "seseorang yang ingin berhasil dalam belajar hendaknya mempunyai sikap serta kebiasaan belajar yang baik karena prestasi belajar yang baik dapat diperoleh melalui proses belajar yang baik". Cara belajar siswa disekolah ataupun dirumah sangat menentukan prestasi belajar yang akan dihasilkan. Cara belajar akan berbanding lurus dengan hasil yang 
Volume I, Nomor 2, Tahun 202 I e-ISSN 2775-5509

didapatkan. Siswa yang mempunyai cara belajar yang baik, aktif, dan disiplin maka akan memperoleh hasil belajar yang memuaskan dan begitu pula sebaliknya. Namun cara belajar yang baik tidak sepenuhnya menjamin prestasi belajar yang baik dan memuaskan. Namun setidaknya dengan mempunyai cara belajar yang baik, diharapkan dapat meminimalisir hasil belajar atau prestasi belajar yang tidak diinginkan.

Berdasarkan hasil pengamatan dan wawancara dengan beberapa siswa dan juga guru bidang studi serta guru bimbingan konseling di Sekolah Madrasah Tsanawiyah Muslimat NU, diketahui masih ada siswa yang menunjukkan sikap kebiasaan belajar dikelas yang bermalas-malasan atau ramai di kelas, tidak memperhatikan, tidak mencatat pokok-pokok materi yang yang telah disampaikan oleh guru, serta mengerjakan tugas pekerjaan rumah (PR) disekolah. Ada juga yang mengantuk, berbicara dengan teman sebangkunya sehingga perhatiannya teralihkan sehingga tidak dapat memperhatikan pelajaran yang sedang berlangsung dengan baik, ketika akan ujian/ulangan semester siswa memiliki kebiasaan hanya akan belajar dengan giat satu hari menjelang ujian atau sistem kebut semalam. Kebiasaan belajar yang diatas berdampak pada nilai hasil prestasi belajar yang didapatkan setelah ulangan tengah semester, nilai ratarata hasil prestasi belajar yang didapatkan banyak yang tidak tuntas atau tidak mencapai KKM (Kriteria Ketuntasan Minimum) yang telah ditentukan. Nilai hasil prestasi belajar ini pun dapat dilihat dari keseluruhan nilai hasil prestasi belajar siswa di dalam Legger yang didapat dari wali kelas..Permasalahan yang terjadi terkait dengan kebiasaan belajar yang berakibat pada prestasi belajar yang rendah tersebut akan berdampak pada keberhasilan siswa dalam pendidikanya apabila terus menerus terjadi.
Menyikapi hal tersebut diperlukan bimbingan dan konseling yang merupakan salah satu aspek dalam bidang pendidikan. Bimbingan konseling mempunyai beberapa layanan yang diimplementasikan dalam sekolah. Salah satu strategi layanan yang dapat diterapkan dalam mengatasi masalah prestasi belajar rendah adalah bimbingan kelompok. Menurut Prayitno (dalam Saputra \& Setianingrum, 2016) bimbingan adalah proses pemberian bantuan yang dilakukan oleh orang yang ahli kepada seseorang atau beberapa orang individu, baik anak-anak, remaja, maupun dewasa agar orang-orang yang dibimbing dapat mengembangkan kemampuan dirinya sendiri dan mandiri, dengan memanfaatkan kekuatan individu dan sarana yang ada dan dapat dikembangkan berdasarkan norma-norma yang berlaku. Prayitno (dalam Yendi et al., 2013) Konseling adalah proses pemberian bantuan yang dilakukan melalui wawancara konseling oleh seorang ahli (disebut Konselor) kepada individu yang sedang mengalami suatu masalah (disebut klien) yang bermuara pada teratasinya masalah yang dihadapi klien. Dapat disimpulkan bahwa Bimbingan dan Konseling adalah proses pemberian bantuan yang dilakukan melalui wawancara konseling oleh konselor kepada konseli yang bermuara pada teratasinya masalah yang dihadapi konseli serta dapat memanfaatkan berbagai potensi yang dimiliki dan sarana yang ada sehingga individu atau kelompok itu dapat memahami dirinya sendiri untuk mencapai perkembangan yang optimal, mandiri serta dapat merencanakan masa depan yang lebih baik untuk mencapai kesejahteraan hidup.

Salah satu layanan bimbingan dan konseling adalah bimbingan kelompok. Sukardi (dalam Yuniarwati, 2018) menjelaskan bahwa layanan bimbingan kelompok adalah layanan yang memungkinkan sejumlah peserta didik secara bersama-sama 
memperoleh bahan dari narasumber tertentu (terutama guru pembimbing atau konselor) yang berguna untuk menunjang kehidupan sehari-hari baik individu sebagai pelajar, anggota keluarga dan masyarakat serta untuk mempertimbangkan dalam pengambilan keputusan. Dengan demikian bimbingan kelompok adalah proses pemberian informasi dan bantuan yang diberikan oleh seorang yang ahli (guru pembimbing) pada sekelompok orang dengan memanfaatkan dinamika kelompok guna mencapai suatu tujuan tertentu, tujuan dalam penelitian ini adalah membentuk konsep diri positif.

Penggunaan teknik dalam kegiatan bimbingan kelompok mempunyai banyak fungsi selain dapat lebih memfokuskan kegiatan bimbingan kelompok terhadap tujuan yang ingin dicapai tetapi juga dapat membuat suasana yang terbangun dalam kegiatan bimbingan kelompok agar lebih bergairah dan tidak cepat membuat siswa jenuh mengikutinya Salah satu teknik yang dapat digunakan dalam layanan bimbingan kelompok adalah self management. Teknik Self Management adalah dimana individu mengatur perilakunya sendiri. Pada teknik ini individu terlibat pada beberapa atau keseluruhan komponen dasar yaitu menentukan perilaku sasaran, memonitor perilaku sasaran, memilih prosedur yang akan diterapkan, melaksanakan prosedur, dan mengevaluasi efektifitas prosedur tersebut (Komalasari \& Wahyuni, 20II).

Bimbingan kelompok dengan teknik self management merupakan lingkungan yang kondusif yang memberikan kesempatan bagi anggotanya untuk menambah penerimaan diri dan orang lain, memberikan ide, perasaan, dukungan bantuan alternatif pemecahan masalah dan mengambil keputusan yang tepat dapat berlatih tentang perilaku baru dan bertanggung jawab atas pilihan yang ditentukan sendiri. Suasana ini dapat menumbuhkan perasaan berarti bagi anggota yang selanjutnya dapat mengubah perilaku yang kurang baik dan mampu berfikir secara jernih.

Adapun dalam menggunakan bimbingan kelompok dengan teknik self-management, diharapkan disamping siswa dapat mencapai perubahan prilaku sasaran yang diinginkan juga dapat berkembang kemampuan manajemen dirinya dalam hal kebiasaan belajarnya, sehingga hasil prestasi belajarnya yang akan didapatkan sesuai dengan yang diharapkan

\section{METODOLOGI}

Tempat penelitian dilaksanakan MTs Muslimat NU Palangka Raya. Penyusunan dari skripsi penelitian ini selama 3 bulan dimulai dari bulan September 2019sampai dengan bulanNovember 2019. Teknik pengambilan sampel dalam penelitian ini dilakukan dengan sampling purposive yaitu teknik penentuan sampel dengan pertimbangan tertentu.

Penelitian ini merupakan jenis penelitian eksperimen mengenai pelaksanaan bimbingan kelompok dengan teknik self-management dalam meningkatkan prestasi belajar siswa kelas IX-B Mts Muslimat NU Palangka Raya. Menurut Sugiyono (2016: 107),”metode penelitian eksperimen dapat diartikan sebagai metode penelitian yang digunakan untuk mencari pengaruh perlakuan tertentu terhadap yang lain dalam kondisi yang terkendalikan”.Sugiyono (2016: menyebutkan terdapat beberapa bentuk desain eksperimen yang dapat digunakan dalam penelitian, yaitu: Pre eksperimental design, true eksperimental design, factorial design, dan quasi eksperimental design.Pada penelitian ini peneliti menggunakan pre eksperimental design. Rancangan eksperimen yang 
digunakan dalam penelitian ini adalah one group pretest and posttest design.

Teknik pengumpulan data yang digunakan dalam penelitian ini yaitu : Angket dan Dokumentasi. Instrument Penelitian yang digunakan dalam penelitian ini adalah angket skala kebiasaan belajar dan legger prestasi belajar siswa IX-B.Angket dalam penelitian ini menggunakan model likert. Model skala likert biasanya terdiri dari 4 jawaban.Teknik analisis data yang digunakan dalam penelitian ini adalah statistik deskriptif. " statistik deskriptif merupakan statistik yang digunakan untuk menganalisis data dengan mendeskripsikan atau menggambarkan data yang terkumpul sesuai dengan fakta tanpa membuat kesimpulan yang berlaku untuk umum" (Sugiyono, 20I2).

\section{HASIL DAN PEMBAHASAN}

Penelitian eksperimen ini bertujuan untuk penelitian ini untuk mengetahui adakah keberhasilan bimbingan kelompok Teknik self-management dalam meningkatkan kebiasaan belajar terhadap prestasi belajar. Penelitian eksperimen ini mengacu pada penggunaan layanan bimbingan kelompok dengan teknik self-management yang dibatasi beberapa tahap saja. Tahap-tahap tersebut meliputi : a) Pemantauan diri (self monitoring) ; b) Reinforcement yang positif (self reward) ; c) Kontrak atau perjanjian dengan diri sendiri (self contracting) ; d) Penguasaan terhadap rangsangan (self control).
Tabel I Perbandingan skor pretest dan Postest

\begin{tabular}{|c|c|c|c|c|c|}
\hline \multirow[t]{2}{*}{ No } & \multicolumn{2}{|c|}{ Pre test } & \multicolumn{2}{|c|}{ Post Test } & \multirow[t]{2}{*}{$\mathrm{D}$} \\
\hline & (\%) & Kriteria & (\%) & Kriteria & \\
\hline I & $45 \%$ & Rendah & $69 \%$ & Tinggi & $24 \%$ \\
\hline 2 & $47 \%$ & Rendah & $67 \%$ & Tinggi & $20 \%$ \\
\hline 3 & $50 \%$ & Rendah & $68 \%$ & Tinggi & $18 \%$ \\
\hline 4 & $55 \%$ & Rendah & $65 \%$ & Tinggi & $10 \%$ \\
\hline 5 & $56 \%$ & Rendah & $68 \%$ & Tinggi & $12 \%$ \\
\hline 6 & $58 \%$ & Rendah & $66 \%$ & Tinggi & $8 \%$ \\
\hline 7 & $56 \%$ & Rendah & $69 \%$ & Tinggi & $13 \%$ \\
\hline 8 & $57 \%$ & Rendah & $72 \%$ & Tinggi & $15 \%$ \\
\hline 9 & $55 \%$ & Rendah & $70 \%$ & Tinggi & $15 \%$ \\
\hline 10 & $59 \%$ & Rendah & $71 \%$ & Tinggi & $12 \%$ \\
\hline $\begin{array}{l}\text { Rata- } \\
\text { Rata }\end{array}$ & $54 \%$ & Rendah & 68,5 & Tinggi & $\begin{array}{c}\mid 4,70 \\
\%\end{array}$ \\
\hline
\end{tabular}

Berdasarkan hasil penelitian dengan menggunakan instrumen kebiasaan belajar siswa sebelum dan sesudah layanan bimbingan kelompok dengan Teknik self-management menunjukkan peningkatan, $\mathrm{Hal}$ ini dapat dilihat pada skor rata-rata Pre-test yang diperoleh sebesar $54 \%$ dan dikategorikan memiliki kebiasaan belajar yang rendah, setelah diberikan layanan bimbingan kelompok dengan teknik selfmanagement terdapat peningkatan persentase menjadi $68,5 \%$ (post-test) dan dikategorikan tinggi.

Selanjutnya berdasarkan Tabel II diketahui bahwa hasil legger Prestasi Belajar Sebelum dan Sesudah pemberian layanan Bimbingan Kelompok Teknik SelfManagement. 
Volume I, Nomor 2, Tahun 2021 e-ISSN 2775-5509

Tabel II Perbandingan skor Legger prestasi Belajar

\begin{tabular}{|c|c|c|c|c|c|c|}
\hline \multirow{2}{*}{ No } & \multirow{2}{*}{$\begin{array}{l}\text { Kode } \\
\text { Siswa }\end{array}$} & \multicolumn{2}{|c|}{ Pre test } & \multicolumn{2}{|c|}{ Post Test } & \multirow[t]{2}{*}{$D$} \\
\hline & & Nilai & Kriteria & Nilai & Kriteria & \\
\hline I & F.M & 67 & $\begin{array}{l}\text { Tidak } \\
\text { Tuntas }\end{array}$ & 75 & Tuntas & 7 \\
\hline 2 & R.N & 68 & $\begin{array}{l}\text { Tidak } \\
\text { Tuntas }\end{array}$ & 75 & Tuntas & 8 \\
\hline 3 & M.R & 70 & $\begin{array}{l}\text { Tidak } \\
\text { Tuntas }\end{array}$ & 77 & Tuntas & 7 \\
\hline 4 & P.I.S & 70 & $\begin{array}{l}\text { Tidak } \\
\text { Tuntas }\end{array}$ & 76 & Tuntas & 6 \\
\hline 5 & F.R.R & 71 & $\begin{array}{l}\text { Tidak } \\
\text { Tuntas }\end{array}$ & 77 & Tuntas & 6 \\
\hline 6 & M.L & 72 & $\begin{array}{l}\text { Tidak } \\
\text { Tuntas }\end{array}$ & 77 & Tuntas & 5 \\
\hline 7 & M.PP.A & 72 & $\begin{array}{l}\text { Tidak } \\
\text { Tuntas }\end{array}$ & 76 & Tuntas & 3 \\
\hline 8 & M.F & 72 & $\begin{array}{l}\text { Tidak } \\
\text { Tuntas }\end{array}$ & 77 & Tuntas & 5 \\
\hline 9 & F.N.F & 73 & $\begin{array}{l}\text { Tidak } \\
\text { Tuntas }\end{array}$ & 76 & Tuntas & 3 \\
\hline 10 & M.G & 72 & $\begin{array}{l}\text { Tidak } \\
\text { Tuntas }\end{array}$ & 78 & Tuntas & 5 \\
\hline Rata & & 70 & $\begin{array}{l}\text { Tidak } \\
\text { Tuntas }\end{array}$ & 76 & Tuntas & 6 \\
\hline
\end{tabular}

Berdasarkan hasil penelitian dengan menggunakan instrumen hasil legger prestasi belajar siswa sebelum dan sesudah layanan bimbingan kelompok dengan Teknik Self-Management menunjukkan peningkatan, hal ini dapat dilihat pada Pre-test skor rata-rata yang diperoleh sebesar 70,I dan dikategorikan memiliki prestasi belajar dalam kategoritidak tuntas, setelah diberikan layanan bimbingan kelompok dengan Teknik Self-Management terdapat perubahan skor rata-rata meningkat menjadi 76,46 (post-test) dan dikategorikan tuntas.

Berdasarkan data yang terkumpul baik dari hasil instrumen kebiasaan belajar dan hasil legger prestasi belajar sebelum dan sesudah mendapatkan layanan bimbingan kelompok dengan teknik Self-Management, langkah selanjutnya adalah menganalisa data dengan menggunakkan rumus uji t-test. Maka perhitungan uji-t taraf kesalahan $\alpha=5 \%$ dengan $\mathrm{dk}=10-1$ diperoleh $\mathrm{t}$ table $=2,262$. Besarnya $\mathrm{t}$ hitung $=-9,6214$ melebihi harga $\mathrm{t}$ tabel; $5 \%$ yakni 2,262. Dapat disimpulkan bahwa data kebiasaan belajar signifikan dan hipotesis penelitian (ha) dapat diterima. Artinya layanan bimbingan kelompok dengan teknik Self-Management dapat meningkat prestasi belajar.

\section{KESIMPULAN}

Dapat disimpulkan bahwa penggunaan layanan bimbingan kelompok dengan teknik self-management dilakukan dengan 4 (empat) tahap meliputi a) Pemantauan diri (self monitoring) ; b) Reinforcement yang positif (self reward) ; c) Kontrak atau perjanjian dengan diri sendiri (self contracting) ; d) Penguasaan terhadap rangsangan (self control). Selanjutnya layanan bimbingan kelompok dengan teknik self management juga terbukti efektif dalam meningkatkan kebiasaan belajar terhadap prestasi belajar siswa di MTs Muslimat NU Palangka Raya. Adapun saran-saran yang dapat berikan untuk sekolah dan guru BK bahwa bimbingan kelompok teknik self management dapat dijadikan sebagai salah satu strategi alternatif dalam meningkatkan kebiasaan belajar terhadap prestasi belajar.

\section{REFERENSI}

Fokusmedia, T. (20I5). Undang-undang SISDIKNAS Sitem Pendidikan Nasional.

Hamalik, O. (2020). Kurikulum dan pembelajaran. Bumi Aksara.

Hanafy, M. (20I4). Konsep belajar dan pembelajaran. Journal.Uin-Alauddin.Ac.ld, I7(I), 66-79. http://journal.uinalauddin.ac.id/index.php/lentera_pendidikan/arti cle/view/516 
Komalasari, G., \& Wahyuni, E. (20II). Teori dan teknik konseling. Jakarta: Indeks.

NK Pratiwi. (2017). Pengaruh tingkat pendidikan, perhatian orang tua, dan minat belajar siswa terhadap prestasi belajar bahasa indonesia siswa smk kesehatan di kota tangerang. Journal.Unas.Ac.Id, http://journal.unas.ac.id/pujangga/article/view/32 0

Rosyid, M., Mansyur, M., IP, S., \& Abdullah, A. (2019). Prestasi belajar. https://books.google.com/books?hl=en\&lr=\&id= 2tmaDwAAQBAJ\&oi=fnd\&pg=PR3\&dq=Rosyid, +Moh.Zaiful+.+(2019).+Prestasi+Belajar.+Malan g+:+Literasi+Nusantara\&ots=WaVVgS9Mgn\&sig $=q X A u 6 O v v v D P S M a e D 3 R 9 L i J P 2 X H Q$

Saputra \& Setianingrum. (2016). Perkembangan motorik halus anak usia 3-4 tahun di kelompokbermain cendekia kids school madiun dan implikasinya pada layanan konseling. Jurnal CARE. http://ejournal.unipma.ac.id/index.php/JPAUD/article/do wnload/536/480

Sugiyono. (20/2). Statistik Untuk Pendidikan. In Statistika Untuk Penelitian.

Yanti. (20I5). PERAN TOKOH WANITA DALAM PENGELOLAAN PROGRAM PAUD AL-BIDAYAH KP. BOJONGKONENG DESA CIBEDUG KECAMATAN RONGGA KABUPATEN BANDUNG BARAT.

Repository.Upi.Edu.

https://I23dok.com/document/yng6k6 I zpengelolaan-program-bidayah-bojongkonengcibedug-kecamatan-kabupaten-bandung.html

Yendi, F. M., Ardi, Z., \& Ifdil, I. (20I3). Pelayanan Konseling untuk Remaja Putri Usia Pernikahan. Jurnal Konseling Dan Pendidikan, I(2), I09-I I4.

Yuniarwati, C. T. (20I8). MENINGKATKAN MOTIVASI BELAJAR MELALUI LAYANAN BIMBINGAN KELOMPOK DENGAN TEKNIK MODELING PADA SISWA KELAS XI A $\urcorner$ Ph I SMK NI CEPU SEMESTER GASAL TAHUN 2017/2018. Empati-Jurnal Bimbingan Dan Konseling, 5(I). 